\title{
Use of Biomass Fuel in Households within Limpopo Province of South Africa and Its Association with Asthma among School Children Aged Thirteen and Fourteen Years of Age
}

\author{
Kidi Rose Maluleke \\ Aalborg University Denmark, The South African Social Security Agency, Research and Development, PO Box 54684, Wierdapark 0149, \\ South Africa
}

\begin{abstract}
Biomass fuel is energy generated from burnt coal, wood, paraffin, dried animal dung and other agricultural waste. These substances when burnt produce toxic substances known to be detrimental to respiratory health. This cross sectional study determined the association of asthma and use of biomass fuel among 742 school children aged 13 and 14 years around Polokwane areas. The prevalence of asthma among the exposed group was $33 \%$. The odds ratio for the association was $1.50, \mathrm{p} 0.01 \mathrm{CI} 1.09 ; 2$. 10. The association was tested under different conditions using regression techniques. In all instances the exposure variable was resilient in predicting asthma, and this way support theories of air pollution and respiratory diseases. Findings of the study suggest complete electrification of areas in Limpopo Province to prevent use of alternative unclean energy sources in order to minimize or eliminate exposure to energy-related respiratory disease agents. For purposes of control, asthma should be made a priority disease and an asthma surveillance system be established in Limpopo Province.
\end{abstract}

Keywords Biomass Fuel, Environment, Asthma, Children, Rural

\section{Introduction}

Burning paraffin, gas, coal, wood and agricultural waste produce toxic gases and particulate matterlike nitrogen oxides, carbon monoxide, carbon dioxide, smoke, methane, sulphur dioxide, nitrogen oxides,PM 1.0 and 2.5, all known to be detrimental to respiratory health. These substances trigger or exacerbate asthma and other allergic diseases. Household environments likepoor ventilation; and host characteristics such as presence of other diseases (asthma, chronic obstructive diseases, pneumonia, diabetes[1] and age[2] are predisposing factors. Many studies were conducted to test the effects of indoor combustion on the pathogenesis, trigger or exacerbation of asthma and other allergic diseases. The majority of the studies were observational (descriptive with an analytical component) rather than experimental. Most studies used proxies of exposure rather than quantitatively -measured exposures, except for the one study by Breysse et al[3] which measured the concentration of particulate matter 1.0, 2.5, nitrogen oxide and

* Corresponding author:

song3four@yahoo.ca. (Kidi Rose Maluleke MSc)

Published online at http://journal.sapub.org/fph

Copyright (C) 2012 Scientific \& Academic Publishing. All Rights Reserved ozone. Since proxies rather than measured toxicants were the exposures, causal factors such as concentrations, duration of exposure and doses could not be determinedhence causal inferences could not be made.

Use of gas stoves, coal stoves, wood stoves, paraffin stoves, open wood or coal fires, gas and paraffin heaters, kerosene heaters were the exposures. In one study[4] researchers simply used "indoor air quality" as the exposure without making reference to sources of the air quality indoors. Methodological diversities implied here may account for inconsistencies in findings of the studies. Thorn et al[5], Kilpelainen et al[6], Eisner et al[7], and Noona et al[8] investigated woodstove and respiratory diseases. Only Thorn et al observed a positive association, odds ratio $1.795 \% \mathrm{CI}$ 1.2-2.5.

Wong TW et al[9] investigated household cooking gas, passive smoking, outdoor pollution, and respiratory illness in children. A dose -response relationship of frequency of cooking with gas and respiratory illness was observed.Phoa et al[10] investigated effects of gas and other fume-emitting heaters on the development of asthma during childhood. These researchers observed that exposure to fume-emitting heaters in early years of life was associated with respiratory illnesses.

The current study investigated the association of asthma and 
use of biomass fuel.As used here biomass fuel refers to energy generated from burnt coal, wood, paraffin, dried animal dung and agricultural waste. It is believed that this study being done in a different contextwill support or negate what is currently known about the effects of air pollution on respiratory health. Energy sources mentioned above, singly or in combination, produce toxic substances, some of them adverse enough to be classified under the Environmental Protection Agency's (EPA) list of criteria pollutants. Table 1 lists air pollutants and their concentrations emitted from biomass fuel, and known to be detrimental to respiratory health.

This study used a sample of 742 children drawn from ten schools in five education districts in the province of Limpopo in South Africa. Children are known to be highly susceptible to asthma and other respiratory illnesses because of the level of their bio-physical development[2].The age group of 13-14 was selected in accordance with the research protocol of the International Study of Asthma and Allergies among Children (ISAAC) that typicallyuses two age groups, the 6-7 years age group and the 13-14 year age group. In this study the older age group was selected in order to keep the cost of the study low, as the younger age group would have necessitated a follow-up into communities to interview their parents or custodians.

The National Heart, Lung and Blood Institute[11] defines Asthma as 'a chronic inflammatory disorder of the airways in which many cells and cellular elements play a role in particular, mast cells, eosinophil, $\mathrm{T}$ lymphocytes, macrophages, neutrophils, and epithelial cells. In susceptible individuals, this inflammation causes recurrent episodes of wheezing, breathlessness, chest tightness, coughing, and abundant mucous production, particularly at night or in early morning. These episodes are usually associated with widespread but variable airflow obstruction that is often reversible either spontaneously or with treatment. The inflammation also causes an associated increase in anexisting bronchial hyper-responsiveness to a variety of stimuli.

Reversibility of airflow limitation may be incomplete in some patients with asthma'.

According to this definition, asthma results from the interaction of inflamed airways, obstructed air flow, and bronchial hyperresponsivesness to many stimuli; and that theseinteractions determine clinical expression of asthma such as wheezing, tight chest and cough[11].

In this study asthma was measured using theAsthma Core Questionnaire of the ISAAC protocol. The questionnaire uses presence of selected symptoms to diagnose presence of the disease.

A question that listed types of indoor energy sources to which the respondents answered "Yes" or "No" was used to measure the predictor variable.

Asthma is associated with factors broadlyclassifiedinto host and environmental factors. Host factors include age, sex, atopy and genetics. Environmental factors include air pollution emitted from a wide variety of sources such as smoking, use of biomass fuel, automobile transport emis- sions, emissions from power generation etc. Environmental factors are defined as triggers, suggesting that inherited potential to develop asthma is a necessary condition. Inherent susceptibility of individuals to asthma explains why people evenly exposed to environmental triggers do not simultaneouslydevelop asthma.

Table 1. Types of air pollutants and their concentrations emitted from biomass fuel and classified as Criteria pollutantsbythe Environmental Protection Agency.

\begin{tabular}{|c|c|}
\hline Pollutant & Concentration \\
\hline Carbon Monoxide & $25-50 \mathrm{Mg} / \mathrm{M} 3$ \\
\hline Nitrogen Dioxide & $0.01-5 \mathrm{mg} / \mathrm{M} 3$ \\
\hline Sulphur Dioxide & $1-3 \mathrm{Mg} / \mathrm{M} 3$ \\
\hline Total Particulate Matter & $0,1-4.2 \mathrm{mg} / \mathrm{M} 3$ \\
\hline
\end{tabular}

Source:A.P.S. Terblancheet al. 1996[12].

\section{Objectives of the Study are to}

1. Determine the Association of Asthma and Use of Biomass Fuel among School-Based Children in Limpopo Province of South Africa.

2. Estimate the Prevalence of Asthma among Children Exposed to Toxic Emissions from Use of Biomass Fuel.

3. Estimate Prevalence of Asthma among the Different Demographic Groups

4. Estimate Measures of Association of Asthma and Exposure to Use of Biomass Fuel.

5. Estimate potential Effects of Other Variables on the Primary Associations of the Study.

\section{Methods}

\subsection{The Study Area}

Limpopo Province is one of the poorest provinces of South Africa[13]. It is predominantly rural. Rural villages and agricultural farming communities comprise the bulk of the provincial land and these are areas where the larger population proportion lives. Table 2 gives details of the rural- urban distribution of the population of Limpopo province.

The study area lies within the District Municipality of Capricorn, within a radius of 60 kilometres around the capital City of Polokwane.The sampled areas are ten schools in five education districts. Schools and districts are distributed variably within a 60 kilometre radius, the majority being located in rural villages. Informal/ traditional housing structures, absence of waterborne sanitation systems, absence of bulk water supplies, lack of proper road infrastructures and absence of bulk electricity supplies characterize rural villages of Limpopo. This is more so as one move further away from the City of Polokwane. 
Table 2. The population counts and proportions Limpopo Province by secondary or small towns and rural areas.

\begin{tabular}{|c|c|c|}
\hline Area & Population in Counts & Percentages \\
\hline Secondary/small towns & 733,748 & 13.20 \\
\hline Rural areas & 4830215 & 86.81 \\
\hline Total & 5563963 & 100.00 \\
\hline
\end{tabular}

Source: PROVIDE Project 2005[14].

Table 3 gives details of proportions of various uses of electricity within Limpopo Province compared to South Africa as a whole.

Table 3 shows that since 1996 up to and including 2007 (year of study), Limpopo Province had lower rates of electricity use in both absolute, and in comparative terms with South Africa as a whole.

Children whom, during the study year (2007), were aged 14 and 13 were born in 1993 and 1994 respectively. At the time of the 1996 Census (when the first survey on electricity was done), they were aged 3 and 2 respectively. It is therefore likely that study children could have been in the group that was exposed to indoor use of biomass fuels at early ages of three and two, when the risk of respiratory diseases in children could have been higher due to incomplete biological development as suggested[2].

Table 3. A comparison of proportions of households using electricity as a source of energy for lighting, cooking and heating in Limpopo Province and in South Africa

\begin{tabular}{|c|c|c|c|}
\hline Uses & $\begin{array}{c}\text { Census/Community } \\
\text { Survey }\end{array}$ & $\begin{array}{c}\text { Limpopo } \\
\text { Proportions }\end{array}$ & $\begin{array}{c}\text { South Africa } \\
\text { Proportions }\end{array}$ \\
\hline Lighting & 1996 & 38.7 & 57.6 \\
\hline & 2001 & 62.9 & 69.7 \\
\hline Cooking & 1996 & 81.0 & 80.0 \\
\hline & 2001 & 20.5 & 47.1 \\
\hline & CS 2007 & 40.2 & 51.4 \\
\hline Heating & 1996 & 19.7 & 44.5 \\
\hline & 2001 & 27.4 & 49.0 \\
\hline & CS 2007 & 36.8 & 58.8 \\
\hline
\end{tabular}

Sources: Community Survey Report 2007 and General Household Survey 2002-2009, 2010[13]

\subsection{Study Design}

Author used a cross sectional design with a weighted andprobability sample of students selected in the study without due regard to exposure or disease status. A multi-stage cluster sampling technique was used for selecting eligible children from the population of study. First, eligible educational districts within the Capricorn District
Municipality were selected as long as they were within the 60 kilometre radius around the capital city of Polokwane. Second, eligible schools within selected districts were chosen based on maximum variability and for having the required age group of 13-14. Third, eligible classrooms within eligible schools were selected on the basis of the presence of the required age group. Finally, eligible students taken from eligible classrooms were selected using the probability proportional to sample (PPS) technique. At each classroom, children who met the criteria for inclusion, namely being aged 13 or 14 years, of unknown exposure status and free from the disease,were selected. Children in the sample were mostly in Grades 7 and 8.Schools for children with special needs were excluded from sampling, so were those whose parents refused to give informed consent.

\subsection{Data Collection}

The Research and Ethics Committee of the University of Pretoria on the $30^{\text {th }}$ November 2006 gave permission for the study, as did the department of Education in Limpopo by allowing access to different schools. In each school, children aged 13 and 14 were called into the school hall where the study was explained to them. Consent forms attached to questionnaires were given to each child to obtain consent to participate in the study from parents or legal guardians. After parental consent was obtained, assent was obtained from the children. Children who did not return the forms to school were considered to have been refused to participate in the study. Before interviews commenced, consent and assent forms were separated from the questionnaire to remove all identifiers.

Research assistants interviewed the participants and recorded the data using structured questionnaires. The completed questionnaires were collected at the various schools, serially numbered and captured. Data validation and verification were done in collaboration with interviewers at the various schools prior to data analysis.

\subsection{Data Analysis}

The objective of the analysis was to determine the association of asthma and use of biomass fuel within households. Exposure to smoke emitted from burnt biomass is one among important predictors of asthma in this study. Others were absence of a waterborne toilet, persistent cough and (to a moderate extent), exposure to hyper allergenic diets.

Pearson's Chi-square tests of association, binary logistic regression and multi-level analyses were used for data analysis. Multilevel analysis used for quantifying variability of asthma at the levels of districts and schools will not be explored in this paper. Data entry and analysis were performed using the statistical package, Stata version 10.

\section{Results}

Table 4 presents demographic and other characteristics of children in the study. 
Table 4. Demographic and other characteristics of children in the study $(\mathrm{n}=742)$

\begin{tabular}{|c|c|c|}
\hline Variable & Frequency & Percentage \\
\hline \multicolumn{3}{|l|}{ Sex } \\
\hline Male & 326 & 43.94 \\
\hline Female & 416 & 56.06 \\
\hline \multicolumn{3}{|c|}{ Age Category } \\
\hline 14 years & 486 & 65.50 \\
\hline 13 years & 256 & 34.50 \\
\hline \multicolumn{3}{|c|}{ Residence Category } \\
\hline Non-village & 21 & 2.83 \\
\hline Village & 721 & 97.17 \\
\hline \multicolumn{3}{|c|}{ Presence of a smoker at home } \\
\hline Present & 202 & 27.22 \\
\hline Absent & 540 & 72.78 \\
\hline \multicolumn{3}{|c|}{ Having tap water at home } \\
\hline Present & 398 & 53.64 \\
\hline Absent & 344 & 43.36 \\
\hline \multicolumn{3}{|c|}{ Waterborne toilet } \\
\hline Present & 181 & 24.39 \\
\hline Absent & 561 & 75.61 \\
\hline \multicolumn{3}{|c|}{ Pet ownership } \\
\hline Present & 276 & 37.20 \\
\hline Absent & 466 & 62.60 \\
\hline \multicolumn{3}{|c|}{$\begin{array}{c}\text { Perceived dust in the living } \\
\text { area }\end{array}$} \\
\hline Yes & 499 & 62.25 \\
\hline No & 243 & 32.75 \\
\hline \multicolumn{3}{|c|}{ Use of biomass fuel at home } \\
\hline Yes & 270 & 36.39 \\
\hline No & 472 & 63.61 \\
\hline \multicolumn{3}{|c|}{ Consume milk } \\
\hline Yes & 677 & 91.24 \\
\hline No & 65 & 8.76 \\
\hline \multicolumn{3}{|c|}{ Consume eggs } \\
\hline Yes & 669 & 90.16 \\
\hline No & 73 & 9.84 \\
\hline \multicolumn{3}{|c|}{ Consume peanuts } \\
\hline Yes & 680 & 91.64 \\
\hline No & 62 & 8.36 \\
\hline \multicolumn{3}{|c|}{ Consume fish } \\
\hline Yes & 709 & 95.55 \\
\hline No & 33 & 4.45 \\
\hline \multicolumn{3}{|c|}{ Family history of asthma } \\
\hline Yes & 96 & 12.94 \\
\hline No & 646 & 87.06 \\
\hline \multicolumn{3}{|c|}{ Family history of allergies } \\
\hline Yes & 287 & 38.68 \\
\hline No & 455 & 61.32 \\
\hline \multicolumn{3}{|l|}{ Asthmatic } \\
\hline Yes & 205 & 27.63 \\
\hline No & 537 & 72.37 \\
\hline \multicolumn{3}{|c|}{ Having a persistent cough } \\
\hline Yes & 227 & 30.59 \\
\hline No & 515 & 69.41 \\
\hline Exposed to chemica & & \\
\hline Yes & 275 & 37.06 \\
\hline No & 467 & 62.94 \\
\hline Socioeconomic s & & \\
\hline Otherwise & 203 & 27.36 \\
\hline Low & 539 & 72.64 \\
\hline Exposure to allerge & & \\
\hline Yes & 479 & 64.56 \\
\hline No & 263 & 35.44 \\
\hline
\end{tabular}

Prevalence of asthma in the sample $(\mathrm{n}=742)$ Asthmatics were $205 / 742$ or $27.63 \%$
Fifty-six per cent $(56.06 \%)$ or 416 children in the study were females. Sixty-five per cent (65\%) or 486 were aged 14 years. The overwhelming majority of the sample, $97.17 \%$ came from villages, but residence did not significantly predict asthma in this study.

The prevalence of asthma in the sample was $27.63 \%$. This is more than what was previously observed in the same area[15]. Mankweng district which is semi-urban had the lowest prevalence of $17 \%$. Maraba being the farthest and more rural had higher prevalence of $35 \%$.

\subsection{Prevalence Estimates and Estimates of Associations in Various Demographic Groups.}

\subsubsection{Age Category}

In the sub-group of children aged 13 years $(n=256)$ the prevalence of asthma was $25.39 \%$ or $65 / 256$. In the sub-group aged 14 years $(n=486)$ prevalence was $29 \%$ or $140 / 486$. The asthma odds ratio for the two groups was 0.84 , $\mathrm{p}=0.32$, CI $0.60 ; 1.19$. This findings show that older age was protective of asthma.

\subsubsection{Sex}

In a sub-group of males $(n=326), 80$ were diagnosed with asthma and the prevalence was $25.0 \%$. Among the sub-group of females $(n=416) 125$ were diagnosed with asthma and the prevalence was $30.0 \%$. The male- female odds ratio was $1.32, \mathrm{p}=0.06$, CI $0.98 ; 1.99$. The finding shows that females were 1.32 times more likely to have asthma than males.

\subsubsection{Category of Residence}

In the sub-group coming from rural villages $(\mathrm{n}=721) 196$ or 27.18 were diagnosed with asthma. In the sub-group coming from suburbs, townships and inner city $(\mathrm{n}=21) 9$ were diagnosed with asthma making a prevalence of $43 \%$. Though numerically smaller, prevalence in this latter group was very high indicating the likelihood of exposure to higher concentrations of multiple, particularly environmental agents.

However if we take the total number of asthmatics $(\mathrm{n}=205)$ in the whole sample $(\mathrm{n}=742)$, only $9(9 / 205)$ or $0.0439 \%$ lived in other areas other than villages. But the majority 196/205 (96\%) lived in rural villages indicating effects of village life on asthma occurrence. The odds ratio for the two groups was 0.51 showing that not coming from rural villages was protective of asthma.

Prevalence among children who did not live in villages was $0.012 \%$. The odds ratio for the two groups was $0.50 \mathrm{p}$ 0.12 CI $0.21,1.20$. This finding suggests asthma was negatively associated with residential category.

The prevalence of asthma was higher in a group that lived in the area since birth i.e. $47.80 \%$ followed by the group that lived in the area from three years onwards with $31 \%$. This finding supports the theory that duration of exposure to air pollutants of certain concentrations is effective in causing 
asthma asKlepeis[16] suggests in his exposure model.

\subsubsection{Use of biomass fuel}

In the total sample $(n=742) 270$ used biomass fuel for energy within their homes, making a prevalence of $36.40 \%$. The prevalence of asthma in this subgroup $(\mathrm{n}=270)$ was $32.96 \%$ or $89 / 270$.

Among the 205 subjects with asthma in the whole sample $(n=742) 89$ or $43.40 \%$ were exposed to use of biomass fuel within their homes.

\subsection{Determining Associations through LogisticRegres- sionanalyses}

\subsubsection{Use of biomass fuel and asthma}

To test whether asthma was associated with use of biomass fuel, a logistic regression analysis was done. This analysis revealed that use of biomass fuel significantly predicted asthma, with odds ratio 1.50 p 0.01 CI $1.09 ; 2.10$, suggesting thatchildren who came from a household using biomass fuel for energy were 1.50 times more likely to have asthma than those who came from households not using biomass fuel for energy.

\subsubsection{Testing the Influence of the Magnitude of Other Odds Ratios in the Model on the Odds Ratio of the Primary Model.}

Theory suggests that the magnitude of the odds ratio of the predictor and outcome variable depends upon the prevalenceof the magnitudes of other variables in the model. Author tested the magnitude of the odds ratio of asthma and biomass fuel in two models. The one model was a saturated model with many predictors irrespective of their significance status (Table 5). The other model was a model with only significant predictors (Table 6).

To test the effects of other predictors on the magnitude of the odds ratio of asthma and use of biomass fuel, a logistic regression analysis was done. Results are shown in Table 5.

Results in Table 5 show that the main predictor retained its resilience in the presence of other predictors. In a model of asthma and use of biomass fuel, the odds ratio was 1.50 , $\mathrm{p}$ value 0.01 , CI $1.09 ; 2.10$. In a model with other predictors the odds ratio was $1.49 \mathrm{p} 0.04 \mathrm{CI} 1.02 ; 2.18$. The difference between the two odds ratios is small showing that the variables in Table 5 did not affect the magnitude of the odds ratio of the primary exposure variable. Thus indicating its resilience.

Results of Table 6 above shows that other significant predictors affected the magnitude of the odds ratio of the primary predictor and the outcome variable, $1.43, \mathrm{p} 0.05$ CI $1.00,2.04$ as against $1.50 \mathrm{p} 0.014$, CI $1.08,2.09$. The differences between the two odds ratios are small indicating the resilience of the primary exposure variable in predicting asthma.
Table 5. Results of logistic regression analysis of asthma and all predictors

\begin{tabular}{|c|c|c|c|}
\hline Predictor & $\begin{array}{c}\text { Odds } \\
\text { Ratios }\end{array}$ & $\begin{array}{c}\text { P } \\
\text { Value }\end{array}$ & $\begin{array}{c}\text { Confidence } \\
\text { Intervals }\end{array}$ \\
\hline Biomasss fuel & 1.49 & 0.038 & $1.02 ; 2.18$ \\
\hline Gender & 1.40 & 0.06 & $0.98 ; 2.00$ \\
\hline Age category & 0.80 & 0.24 & $0.55 ; 1.16$ \\
\hline Smoker at home & 1.31 & 1.17 & $0.89 ; 1.92$ \\
\hline Running water & 1.16 & 0.46 & $0.78 ; 1.72$ \\
\hline Waterborne toilet & 0.53 & 0.00 & $0.34 ; .84$ \\
\hline Pet ownership & 1.00 & 0.99 & $0.69 ;$ \\
\hline Dusty environment & 0.97 & 0.87 & $0.65 ; 1.42$ \\
\hline Consumes milk & 2.03 & 0.02 & $\begin{array}{c}1.12 ; \\
4.74\end{array}$ \\
\hline Consumes eggs & 1.86 & 0.08 & $0.92 ; 3.70$ \\
\hline Consumes cheese & 2.04 & 0.04 & $1.05 ; 3.99$ \\
\hline Consumes fish & 0.88 & 0.77 & $0.38 ; 2.06$ \\
\hline Consumes peanuts & 1.36 & 0.39 & $0.67 ; 2.79$ \\
\hline Family history of asthma & 0.82 & 0.46 & $0.48 ; 1.38$ \\
\hline Family history of allergies & 1.19 & 0.34 & $0.83 ; 1.71$ \\
\hline Persistent cough & 4.15 & 0.00 & $2.89 ; 5.96$ \\
\hline Exposure to hyper allergenic & 0.31 & 0.00 & $0.15 ; 0.64$ \\
\hline diets & & &
\end{tabular}

Table 6. Results of logistic regression analysis of asthma and the main predictor and other significant predictors

\begin{tabular}{|l|c|c|c|}
\hline \multicolumn{1}{|c|}{ Variable } & Odds ratio & P value & $\begin{array}{c}\text { Confidence } \\
\text { Interval }\end{array}$ \\
\hline Use of biomass fuel & 1.43 & 0.05 & $1.00 ; 2.04$ \\
\hline Waterborne toilet & 0.576 & 0.00 & $0.39 ; 0.85$ \\
\hline Persistent cough & 3.96 & 0.00 & $2.80 ; 5.61$ \\
\hline $\begin{array}{c}\text { Exposure to allergenic } \\
\text { diets }\end{array}$ & 0.73 & 0.08 & $0.52 ; 1.03$ \\
\hline
\end{tabular}

\subsubsection{Adjustment for Confounding}

A review of literature shows that variables such as age, gender, place of residence are potential confounding variables[17]. As a result a logistic regression to test for confounding was done. Table 7 gives details.

Table 7. Results of adjustment for confounding

\begin{tabular}{|c|c|c|c|}
\hline Asthma & Odds Ratio & P value & Confidence Intervals \\
\hline Smoke & 1.61 & 0.00 & $1.15,2.25$ \\
\hline Age cat & 0.82 & 0.27 & $.58,1.16$ \\
\hline Gender & 1.33 & 0.09 & $.953,1.85$ \\
\hline Residence & 1.36 & 0.03 & $1.03,1.80$ \\
\hline
\end{tabular}

The results of table 7 showed that the adjusted odds ratio is moderately larger than the unadjusted odds ratio $1.61 \mathrm{vs.}$ 1.50 suggesting that the variables age, gender and place of residence, were confounders of the association of asthma and use of biomass fuel for energy.

However results in Table 5 and 6 showed the resilience of the primary factorin predicting asthma.

\section{Discussions}

The prevalence of asthma in the sample was 27.63 or $205 / 742$. The findings on age, sex and use of biomass fuel, as far as they relate to susceptibility to asthma, support what is 
currently known.

\subsection{Age and Asthma}

Sixty five per cent of the sample was aged 14 years. The odds ratio of 0.84 suggests that higher age was protective of asthma. This finding supports several theories of children's susceptibility to asthma. One such theory suggests that incomplete biological development of small children(particularly their undeveloped immune defence systems and developing lungs) increase their susceptibility to asthma and other respiratory diseases[2, 18].Another theory suggests exposure to inspirable toxic pollutants in early years of life leads to atopy and sensitization of the respiratory system[19]. Theories of asthma development also suggest that airway inflammation, whether inherited or acquired from the environment, if it happens before the age of three years, sets the stage for development of asthma by 6 years of age or later[11].Author is of the opinion that most 13 and 14 year old children in the study were exposed to toxic air pollutants during their early years and that this exposure may have been due to lower rates of electrification in Limpopo province as shown in Table 3.

\subsection{Gender and Asthma}

Fifty six per cent $(56.06 \%)$ or $416 / 742$ respondents were females. The prevalence of asthma within this group was $30 \%$ or $125 / 416$. Female asthmatics comprised $61 \%$ or $125 / 205$ of the sub-sample of all asthmatics in the study. The odds ratio of female-male asthma was 1.32 , p 0.06 , CI $0.98 ; 1.99$. The finding shows that girls were 1.32 times more likely to have asthma than boys.

This finding is not consistent with the generally held perspective that boys aremore susceptible to asthma than girls. The National Heart, Lung and Blood Institute[11] suggested that at younger ages males are more at risk than females. Harwood[20] also suggested boys are susceptible to asthma before the age of 14 years. Some studies also showed rates of asthma, wheezing, and rhinitis and hay fever symptoms to be higher in boys than girls in cities with high humidity and in cities with low humidity[21].Another theory suggested that lungs of boys are smaller during younger ages when compared with those of girls at same ages, making boys more susceptible to asthma at younger ages[22].

\subsection{Use of Biomass Fuel and Asthma}

Thirty six per cent or 270/742 of the sample used biomass fuel for energy within their homes. The prevalence of asthma within this group was $32.96 \%$ (or $89 / 270$ ).

A logistic regression of asthma and use of biomass fuel yielded an odds ratio of 1.50 , p 0.014 CI 1.86; 2.97 suggesting that use of biomass fuel significantly predicted asthma in this sample.

When adjusted by age, gender, residence, the odds ratio for use of biomass fuel and asthmawas 1.61 , p 0.00, CI 1.15; 2.25 suggesting that the crude and adjusted odds ratio did not differ much (1.50vs. 1.61).
Looking at the data above, it is clear that the main study variable predicted asthma significantly and that potential confounders age, gender and residence did not significantly affect the relationship of asthma and use of biomass fuel.

This finding supported what is already known about the effect of burnt biomass on respiratory health: Burnt wood, coal, paraffin, gas, dried animal waste and agricultural waste produce toxic substances. Burnt paraffin and wood emit methane, nitrogen dioxide, nitric acid; carbon monoxide and carbon dioxide are emitted as cooking fumes[23]. Burnt coal emits carbon dioxide and carbon monoxide, dozens of polycyclic hydrocarbons and particulate matter[24].Household cooking stoves with or without ventilation, produce enough pollutants to significantly affect local neighbourhoods[25]. Nitrogen oxide combines with water to form acids that damage lung tissue. It also combines with sulphur dioxide to form inspirable particulate matter (sulphates and nitrates)[26]. Nitrogen dioxide exacerbates asthma and causes death among asthmatics[27]. Sulphur dioxide irritates respiratory tracts and causes airways to close and disrupt lung function[28]. Ozone damages the lungs, causes coughing, and in asthmatic patients, causes exacerbations. It also compromises the immune system and causes shortness of breath and painful breathing[29]. Fossil and biomass fuel[wood and coal] inflame airways and cause them to constrict resulting in breathing difficulties[30]. Fine and ultra-fine inspirable particulate (PM 1.0, 2.5) lodge deeper into lungs and incur damage to lungs[31]. A mixture of toxic pollutants can cause allergic sensitization to healthy individuals and to those who have chronic obstructive diseases[32]. When inhaled, carbon monoxide reduces the ability of the blood to bring oxygen to body cells and tissues[33]. Carbon dioxide inflames airways and causes them to become constricted resulting in breathing difficulties. It also irritates respiratory mucosa and increases sensitization to allergens[34].

The evidence presented in this study suggests that if rural children continue to be exposed to substances that burnt biomass produces, the risk of asthma in Limpopo province will remain high. Given that sick children become sick adults, Limpopo province may confront a phenomenon of insufficient healthy manpower to carry out development tasks.

\section{Conclusions}

If findings of this study and that of Maritz[15], both having been done in the District Municipality of Capricorn, are taken together; and given that The District Municipality of Capricorn which contains Polokwane, the capital city of Limpopo, is relatively developed and urbanized compared to the remaining 4 district municipalities of Vhembe, Waterberg, Mopani and Sekhukhune (Figure 1) below, it can be concluded that the risk of asthma in Limpopo is significantly high. This makes asthma a major public health issue that should be prioritized for prevention and control. Such measures should include establishment of an asthma sur- 
veillance system and that the disease be made notifiable. Under such circumstances it will be possible for Limpopo government to identify the risk factors for asthma among children. Inadequate electrification leading to use of biomass fuel for energy (one of the major risk factors), will be highlighted and targeted for intervention.

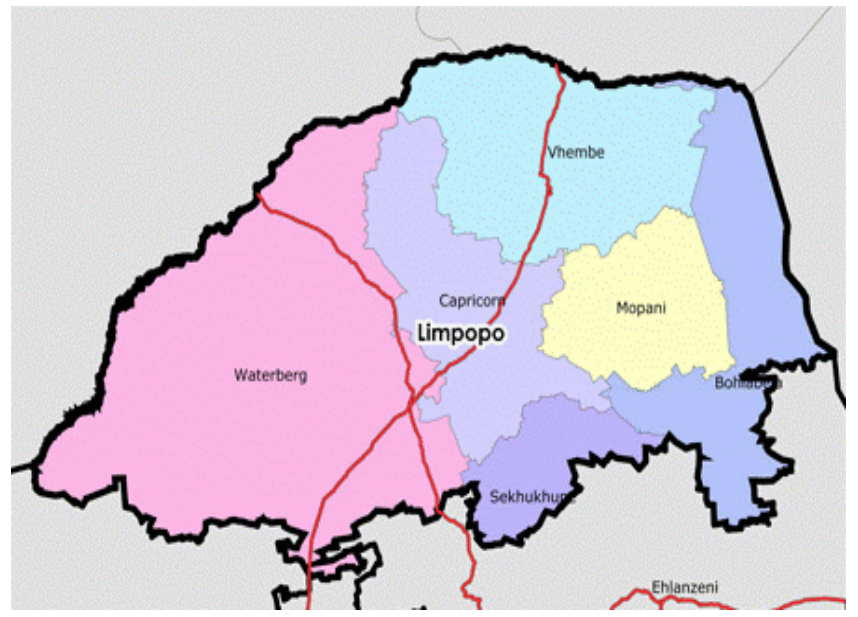

Source: Demarcation Board (www.demarcation.org.za) in PROVIDE Project[5]

Figure 1. Map of Limpopo Province showing all District Municipalities

\section{ACKNOWLEDGEMENTS}

Tsakani Trust for providing the supporting grant.

\section{REFERENCES}

[1] A.D.Kappos, P. Bruckmann,E.Eikmann, N. Englert, U. Heinrich, P . Hoppe, Koch, G.H.Krause, W.G. Kreyling, K. Rauchfuss, P. Rombout, V. Schultz-Klemp, W.R. Thiel, E.H.E. Wichman (2004). "Health Effects of particles in ambient air". International Journal of Hygiene and Environmental Health:Volume 207, Issue 4, 399-4070.

[2] L.Trasande, G.D.Thurston (2005). "The role of air pollution in asthma and other pediatric morbidities". Journal of Allergy and Clinical Immunology: 115, Issue 4, 689-699.

[3] P.N.Breysse, T.J.Buckley, D.Williams, C.M. Beck, S. Kanchanaraksa, L.J. Swartz, K.A. Callahan, A.M. Butz, C.S. Rand, G.B. Diette, J.A. Krishnan, A.M. Mosely, J. Curting-Brosnam., N.B. Durkin, P.A. Engelson (2005). "Indoor exposures to air pollutants and allergens in the homes of asthmatic children in Inner- City Baltimore". Environmental Research: Volume 98, Issue 2, 167-176.

[4] W. Jedrychowski, U. Maugeri, I. Jedrychowska-Bianchi, E. Flack (2005)."Effects of indoor air quality in the post-natal period on lung function in pre-adolescent children" "A retrospective study in Poland. Public Health: Volume 119, Issue $6,535-541$.

[5] ThornJ. Brisman, K. Toren (2001). "Adult-onset asthma is associated with self-reported mold or environmental tobacco smoke exposures in the home'. Allergy: 56 (4), 287-292.
[6] M. Kilpelainen, M. Koskenvuo, H.Helenius (2001).“Wood stove heating, asthma and allergies". Respiratory Medicine:95, 911-916.

[7] M.D. Eisner, E.H. Yelin, P.P. Katz, G. Earnest, P.D. Blanc(2002) "Exposure to indoorcombustion and adult asthma outcomes: environmental tobacco smoke, gas stoves, and wood smoke" Thorax:57, 110, 973-976.

[8] C.W. Noonan, T.J. Ward (2007)."Environmental tobacco smoke, woodstove heating and risk of asthma symptoms". Journal of Asthma:44, 9, 735-738.

[9] T.W.Wong, T.S Yu, H.J. W.Tam, I Tak Sun You, Y.T.Wun, A.H.S.Wong, C.M.Wong (2004)."Household gas cooking: a risk factor for respiratory illness". Archives of Disease in childhood: $89,631-636$.

[10] L.L. Phoa, B.G. Toelle, K. NG, G.B. Marks (2004). "Effects of gas and other fume emitting heaters on the development of asthma during childhood". Thorax: 59, 9, 741-745.

[11] National Heart, Lung and Blood Institute (2007). National Asthma Prevention Program. Expert Panel Report 3. "Guidelines for the Diagnosis and Management of Asthma". Full Report. US Department of Health and Human Services. National Health institute. www.nhlbi.nih.gov/guidelines/asthma/asthgdln.Downloaded June 252010

[12] A.P.S. Terblanche (1996) In C. Van Horan. "Indoor air pollution from coal and wood use in South Africa". An Overview Reprinted from Energy for Sustainable Development. Journal of International Energy Initiation. 111,1.

[13] Statistics South Africa (2007). "Community Survey". Statistical Release P0 301. Pretoria;Statistics South Africa (2010). General Household Survey Series Volume 11: Housing 2002-2009. In-depth Analysis of the General Household Survey Data. Report Number 03-18-01 (2002-20090. Pretoria.

[14] The PROVIDE Project. The Provincial Decision Making Enabling Project. Background Paper Series. Background Paper 2005: A Profile of Limpopo Province: Demographics, Poverty, Inequality, and Unemployment. Elsenburg 2005. Project Leader, Cecilia Punt. Senior Researcher, Kalie Pauw, Melt van Schoor.Young professional, Bonani Nyhodo.Technical Expert. Schott McDonald. Associate Researchers, Lindsay Chant, Christine Valente.

[15] C. Maritz (2005). "The prevalence of asthma and allergic rhinitis in school -going children in Polokwane, Limpopo, South Africa". Research Report for the Master of Public Health, School of Health Systems and Public H, Faculty of Health Sciences, University of Pretoria.

[16] N.E.Klepeis (1999). "An introduction to the indirect exposure assessment method of modeling human exposure using micro-environment measurement and the recent National $\mathrm{Hu}-$ man Act Survey". Environmental Perspective: 107 (Supplement 2), 365-374.

[17] G.B.Burt (1998). "Epidemiology Kept Simple". "An Introduction to Classic and Modern Epidemiology". John Wiley \& Sons: New York. Pages 187-196.ISBN: 0-471-24029X.

[18] P. Illig, D.P. Haldeos (2004).Children's Heath and the Environment. Journal of Development, 47 (2) 104-108.

[19] E. Von Mitius (2002). "Environmental factors influencing the 
development and progression of pediatric asthma". Journal of Allergy and Clinical Immunology.109, s527-s528

[20] L.J. Harwood, D.M.F.TFergusson (1985). "Social and Familial factors in the development of early childhood asthma". Pediatrics:75, 5, 859-868. Cited in M. Mossoli, D. Fabian, S. Hol, Beasley (2004). The Global Burden of Asthma. Developed for the Global Initiative on Asthma (GINA). Institutions Represented in the Report are the Medical Research Institute of New Zealand, Wellington, University of Southampton UK. Downloaded from www.iol.co.za Health, May 4.

[21] B. Kaur, J.B.Austin, H.R. Anderson. Burr, L.S. Harkins (1998). "Prevalence of asthma symptoms, diagnosis, and treatment in 12-14 year old children across Great Britain". International Study of Asthma and Allergies in Childhood (ISAAC UK). BMJ:316, 118-124.

[22] C.Almaqvist, M. Worm, B. Leynaert (2008). "A GA2 LEN Review”. IngentaConnect www.ingentaconnect.com. Downl oaded 4/11/08. Sourced from Allergy: 63, 1, 11, 47-57.

[23] V.Mishra (2003). "Effect of indoor air pollution from biomass combustion on prevalence of asthma in the elderly". Environmental Health Perspective: 111. a

[24] Environmental Protection Agency. Queensland Government: Environmental Protection Agency / Queensland Parks and Wildlife Service. "Nitrogen Oxides.www.epa.qld.gov.au/env ironmental management air/air_quality_monitoring/air”.Downloaded 16/02/2006.

[25] K.R.Smith (2000). "National burden of disease in India from indoor air pollution”. PNAS: 97, 24.

[26] Air Pollution Fact Sheet www.wwfpak.org/factsheet_aps.php. Downloaded, 16/02/2006.
[27] J.Sunyer, X. Basagana, J. Belmonte, J.M.Anto (2002). "Effect of nitrogen dioxide and ozone on the risk of dying in patients with severe asthma". Thorax: 57, 687-693.

[28] J.M.Last (1998) 2nd ed. "Public Health and Human Ecology". Appleton \& Lange, Stamford, Connecticut.

[29] Wayne et al (2002). Cited in Medscape Today. Issue: "Is Asthma Rise an Early Impact of Anthropogenic Climate Change?" "Elevated CO 2, Climate Change Impacts on Pollen".Www.medscape.com. Environmental Health Perspectives 2005 .

[30] J.M.Neidell (2004). "Air pollution, health, socioeconomic status: effects of outdoor air quality on childhood asthma". Journal of Health Economics: Volume 23, Issue 6, 1209-1236.

[31] www.asthamcare.com. Downloaded 17/05/07

[32] McConnell, K. Berhane, Gilliland, J. Stephanie, W.J. Gauderman (2002). "Asthma in exercising children exposed to ozone: a cohort study". The Lancet: 359, Issue, 9304, 386-391.

[33] Venn et al (2001). Cited in Medscape Today. Issue: "Is Asthma Rise an Early Impact of Anthropogenic Climate Change?" "Elevated CO2, Climate Change Impacts on Pollen. Environmental Health Perspectives: 2005, 113 (8): 915-919. Www.medscape.com. Downloaded 14/03/2006.

[34] Janssen, A.H.Nicole, B.Brunekreef, P.Van Vliet, F.Aarts,K.Meliefste, H.Harssema, P. Fischer (2003). "The relationship between air pollution from heavy traffic and allergic sensitization, bronchial hype responsiveness, and respiratory symptoms in Dutch school children". Environmental Health Perspective September 12, 111, 1512-1518. 